\title{
PAULO HENRIQUES BRITTO E LUCIAN FREUD, CONTRABANDO OU INTEGRAÇÃO?
}

\author{
Lélia Parreira Duarte*
}

[...] não há nada de que eu mais goste de insinuar do que a presença da ternura numa noite sobre a qual me contaram o suficiente para que possa agora reconstruí-la, contá-la a partir do meu próprio Hades, esse reino dos mortos particular que existe em cada um de nós.

Henrique Vila-Matas, Ar de Dylan

Quando recebi o convite para participar deste evento, "Contrabandos da cultura», o que muito me honrou e que agradeço, encantou-me o que entendi como uma grande convergência de duas obras com a proposta do colóquio. Trata-se da pintura de Lucian Freud e do último livro de poesia de Paulo Henriques Britto, Formas do nada, numa relação, portanto, entre imagens e textos.

Pensei inicialmente no poema "Man in a chair (Lucian Freud)", de Formas do nada, de Paulo Henriques Britto (2012, p. 41), e no quadro de Lucian Freud (1998. Óleo sobre tela, $110 \times 90,6$ cm.), a que o poema de Britto se refere.

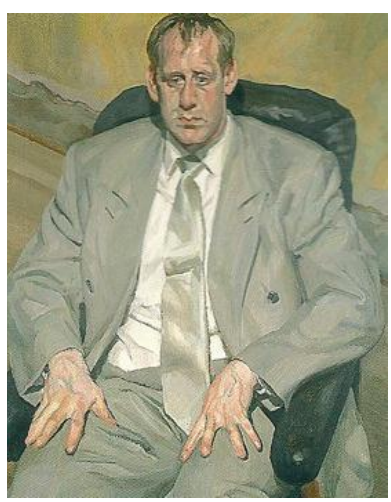

Man in a chair, Lucian Freud

* Professora da Universidade Federal de Minas Gerais. 


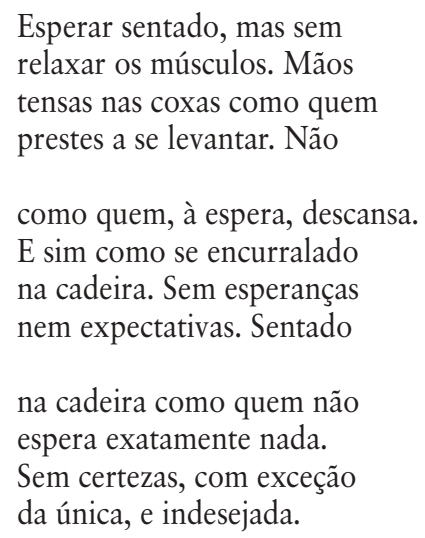

Ambos tratam do paradoxo de a falta de esperanças impulsionar a criatividade: a expectativa da morte, sem o consolo da religião ou dos mitos, causa horror, mas é ao mesmo tempo algo que fascina e potencializa a criação. Pois torna o homem «livre do ser», já que o «não-ser» abre a possibilidade de reconhecer a debilidade do outro e, em decorrência, a fragilidade própria do eu. Ambas as obras reconhecem que ao artista resta aprender a conviver com os demônios fora do paraíso, desistindo, para criar, da ordem divina e de todas as esperanças a ela inerentes. Fazem lembrar por isso Agamben, para quem a linguagem (tanto literária quanto pictórica, certamente) tem como função apenas o anúncio da finitude, na sua perseguição do objetivo de testemunhar o intestemunhável.

As produções de Lucian Freud e de Paulo Henriques Brito enfrentam corajosamente e de peito aberto essa finitude, mostrando como a certeza da morte está incorporada na sua consciência e, ainda, que o fazer artístico permite uma convivência harmoniosa com essa marca do ser humano. Registram assim a perspectiva artística e filosófica de um tempo marcado pelo gozo de um prazer terrível: a consciência da perda (ou da ameaça de perda) e da própria dor, únicos elementos capazes de transformar o artista em um momento de passagem ou de ultrapassagem da fragilidade da dimensão humana, sempre ameaçada pelo não-ser.

No quadro de Lucian Freud «Homem com fato prateado», vemos uma figura aparentemente estática, mas com sugestão de um impulso de movimento contido e impotente, como se repetisse o dito de Bartleby, a personagem de Melville: «Preferiria não o fazer.» Ou como se concordasse com Bataille: «deveríamos libertar o animal acorrentado dentro de nós» (cf. SeligmanN-Silva, 2008, p. 30).

O quadro retrata uma figura máscula, bem vestida, com um fato prateado, o que sugere distinção e até nobreza. Sentado, como se fosse levantar-se, esse homem quase chega a marcar uma diferença na obra de Freud, um artista que pinta geralmente o corpo em repouso. $\mathrm{O}$ impulso é entretanto contido e sugere indecisão, e mesmo medo e desânimo, sendo que os tons do quadro reforçam a 
ideia de desesperança e depressão. $\mathrm{O}$ aparente impulso vital que parece existir na figura acaba por revelar uma tensão irresolvida que sugere incertezas ou desesperanças, como se the faltasse a autonomia que supostamente caracteriza o ser humano.

É interessante observar a análise feita por Paulo Henriques Britto (2012, p. 41) dessa figura que ele chama «Man in a chair (Lucian Freud)»: para o poeta, esse homem estaria prestes a levantar-se de uma cadeira que mais parece uma prisão (nela o homem está «encurralado", como um animal (bravio?). Paradoxalmente, poderíamos acrescentar: é como se o fato de expor a situação numa pintura ou falar dela num poema fossem atos de coragem que pudessem exorcizar o indesejado mal, através da criação.

E como faz Britto a sua análise da tela de Lucian Freud? Deixando para outro momento análise mais detalhada do poema, por motivo de espaço, observo que ele é feito de doze octossílabos, reunidos em três estrofes de quatro versos; praticamente todos eles constroem-se com enjambements, como que revelando uma ligação irreversível entre as comparações. Negativamente, falam de sugestões (contidas) de movimento, espera e descanso; já o encurralamento e a falta de expectativas aparecem como afirmações que apontam para a certeza da angústia, da impossibilidade, da impotência.

Tanto no quadro de Freud quanto no poema de Britto, portanto, a vida de que se fala é sem repouso ou esperanças, aponta para o fim. Mas essa negatividade, que lembra Baudelaire - o poeta do feio e do putrefato, do negativo - indica a possibilidade de o homem ficar «livre do ser», para ser capaz de criar e então poder vencer a morte.

Lucian Freud é um pintor de disparidades e não de concordâncias, como parece mostrar a sua «Cabeça de rapaz» (1952. Óleo sobre tela, 21,6 $\times 15,9 \mathrm{~cm}$.): o desânimo tem aí também forte presença, marcando-se especialmente pela mão em que praticamente se enterra o rosto, numa estaticidade de quem nada tem a esperar. A expressividade dos olhos, entretanto, parece revelar uma aceitação de um eu que se assume, apesar de todo o estranhamento e desconforto, o que equilibra notavelmente a pintura.

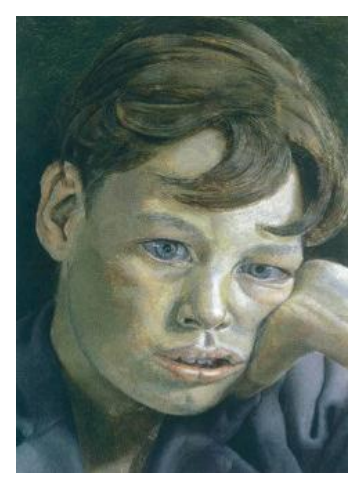


E mais uma vez encontro um poema de Paulo Henriques Britto que parece casar-se bem com essa pintura. Trata-se do poema VII, de «Biographia literária» (2012, p. 35):

\section{VII}

Nada disso foi do jeito que eu quis. Se fosse como eu quis, não haveria de ser tão sofrido, tão infeliz.

Mas eu - o eu que sou - eu não seria.

Assim, não me lamento. Até me sinto como quem tem não o que foi pedido, e sim o que, guiado pelo instinto, não pelo querer, teria querido.

O que de mais duro a vida me deu - que dura mais quanto mais me custou dele me acostar, e torná-lo meu -

o que não escolhi, mas me escolheu, é o que, ao fim e ao cabo, mais eu sou.

Não é o eu que eu me quis. Mas sou eu.

Esse eu que fala no poema poderia ser o da «Cabeça de rapaz»: desejou ser forte e feliz e teve decepções. Reconhece a importância do instinto, mas principalmente do sofrimento e do não - da negatividade, da dureza, da infelicidade responsáveis afinal pela construção do seu eu, da sua identidade: algo em constante movimento, feito mais pelo não querer que pelo desejo.

E assim as duas obras lembram Orfeu, cujo lema poderia ser: «de que adianta cantar»? Orfeu sabe que o canto não recuperará a sua amada Eurídice, ele é uma afirmação do vazio de sua presença e uma testemunha de sua frustração, de sua vida perdida. Para Blanchot, em «O olhar de Orfeu», Eurídice representa o extremo que a arte pode atingir; ela é o ponto profundamente obscuro para o qual parecem tender a arte, o desejo, a morte, a noite, mas representa também o ponto brilhante que escapou a essa espera (cf. BLANCHOT, 1987, pp. 171-176).

O canto de Orfeu, ou a poesia de Britto, ou a pintura de Lucian Freud (ou a arte contemporânea em geral?) parecem fazer-se portanto de uma linguagem que só pode falar de perda, de falta e de expectativa do fim. Não aparece aí a tradição do belo, do real agradável, mas algo terrível e até repugnante. Entretanto, é como se a angústia e a depressão, contraditoriamente, trouxessem ao artista a vigorosa energia que o leva à produção. Giorgio Agamben diz que somos capazes de criar apenas quando conseguimos «fazer experiência de nossa própria impo- 
tência». Para ser poeta (artista), diz o filósofo, o mais difícil «não são o nada e as suas trevas [...] - o mais difícil é sermos capazes de anular este nada para fazer ser, do nada, alguma coisa» (cf. AgAmBen, 20-, p. 24).

Várias outras telas de Lucian Freud e diversos outros poemas de Formas do nada, de Paulo Henriques Britto, ilustrariam, a meu ver, essa importante função da arte, a de «livrar-nos de ser», assim resumida nas palavras de Fernando Pessoa, no Livro do desassossego: "A arte livra-nos ilusoriamente da sordidez de sermos.»

Em Homem Ruivo numa Cadeira (1962/63. Óleo sobre tela, 91,5 × 91,5 $\mathrm{cm})$, a figura parece deslocada e amedrontada, sem esperanças nem expectativas. Encolhido e como que também encurralado, esse homem (que usa, como o "Homem com fato prateado", um terno cinza), é outra vez a imagem da impotência e do medo, como se nada pudesse esperar do futuro.

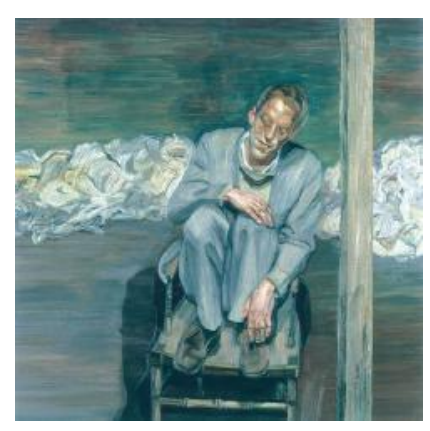

Também a Mãe do Pintor a Descansar (1982-1984. Óleo sobre tela, $105,4 \times 127,6 \mathrm{~cm}$.) parece tensa. Tem a linha dos maxilares bem acentuada, o olhar fixo mas vazio, num descanso que não parece descansar, numa espera desesperançada de quem nada tem a esperar. Está ali, simplesmente. É o que é, lembra por isso um próximo aniquilamento do ser, e ainda o seu apodrecimento que, como diz Bataille, lança as carnes mortas na fermentação da vida» (cf. SILVA, 2008, p. 160).

O pintor revela o prazer de sua própria dor e, ao mesmo tempo, a dimensão da sua ternura. A depressão em que a mãe vivia após a morte do marido é retratada por ele sem sentimentalismos, em numerosas telas; sua imobilidade a transformou num excelente modelo para o filho, que confessou pintá-la também para a animar, dar-lhe alguma coisa para fazer. "O meu trabalho é puramente autobiográfico», disse ele. «É sobre mim próprio e o que me envolve. É a tentativa de um testemunho. Eu trabalho a partir de pessoas que me interessam, e que me são queridas.» (SMEE, 2010, p. 7) 


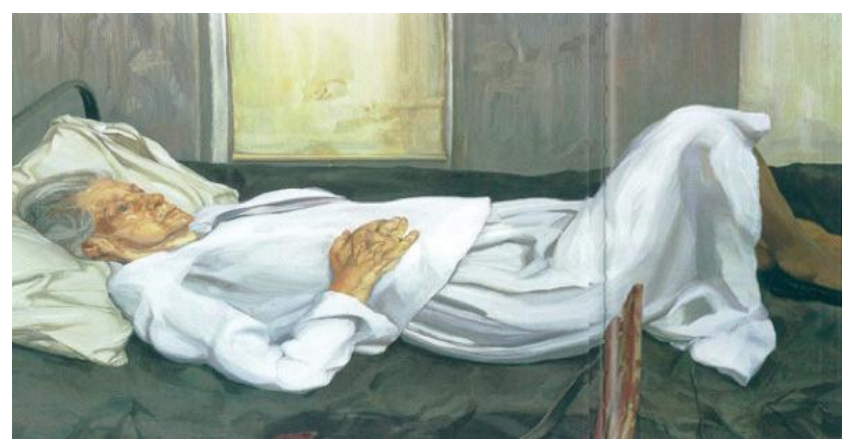

Sintomaticamente, acrescenta que o cansaço dos seus modelos lhe dá energia, pois lhe interessa testemunhar a desilusão, a desistência, observar o desânimo e o "preferiria não o fazer», que o fascinavam e induziam à criação. Pintando a tristeza da mãe, o pintor se une ao seu modelo, que afinal não é mais um outro: é como se fosse ele mesmo, um animal humano próximo do fim.

Vale lembrar nesse sentido os auto-retratos do pintor, especialmente o Pintor a trabalhar, reflexo (1993. Óleo sobre tela, 101,6×79,4 cm.), que mostra o pintor nu, de pé, usando apenas um par de botas sem cadarços e tendo nas mãos uma paleta e uma espátula. A evidente sobreposição de várias camadas de tinta acentua a obscuridade da figura, o que acaba por sugerir um animal que mal se sustenta de pé e quase se desmancha, num apodrecimento. Mas que, paradoxalmente, é capaz de ultrapassar o anúncio do não-ser.

O poema III, de «Três peças dispépticas», de Paulo Henriques Britto (2012, p. 59), em sua insistência na falta de objetivo, parece combinar bem com aquele estático Homem ruivo numa Cadeira, com a Mãe do Pintor a Descansar e ainda com outros quadros de Lucian Freud:

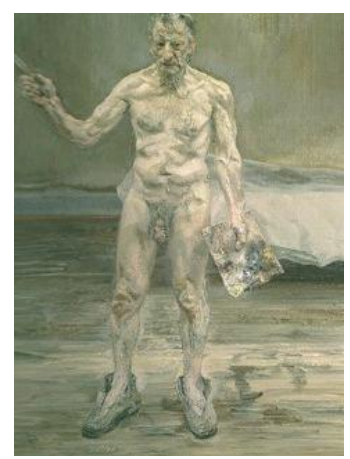


III

Não fosse por isso

por outra seria.

Não tem, desde o início,

teleologia

nem origem, causa

ou motivação.

Avança sem pausa

rumo à conclusão,

a qual é um fim

sem finalidade.

E termina assim.

Pronto. Já vai tarde.

A potência da negatividade impulsiona o poema, cuja linguagem se exercita num humor ácido, com um final quase agressivo, afirmando o propósito de ficar em si mesmo, sem mensagens nem esperanças (como as duas referidas telas de Lucian Freud?).

Também o poema IV, de "Quatro bagatelas», de Paulo Henriques Britto (2012, p. 65), poderia alinhar-se com quadros de Freud:

\section{IV}

Vida sempre rascunho, folha sem pauta, pasto de lacunas e rasuras, risco sobre risco, pré-texto de nada.

\section{Freud}

Rapariga nua (1966. Óleo sobre tela, $61 \times 61 \mathrm{~cm}$.) é outro quadro de Lucian

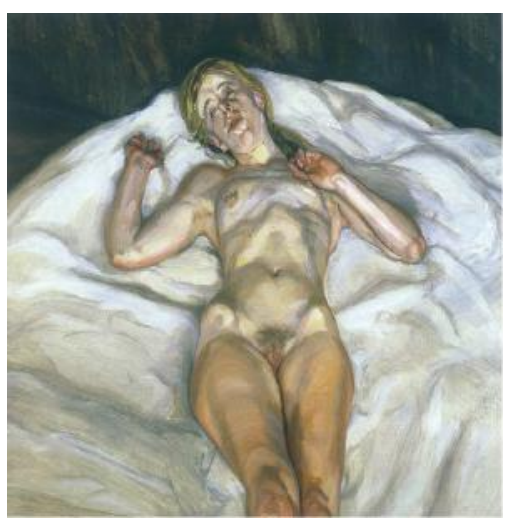


a mencionar nesta comparação. Indica o interesse do artista pelo corpo feminino, que ele pinta fracionado em manchas, deixando registrada a direção e a pressão exercida sobre o pincel. Embora exposta em detalhes que marcam a sexualidade, essa mulher nua não convida a desejos ou repugnâncias lascivas. Magra, triste e amedrontada, aparentemente sem forças, decadente e sem esperanças ou expectativas, é apenas o testemunho de um corpo nu, ou melhor, de um retrato nu, que mostra bem o que é e como é feito. O que lembra um dito de Lucian Freud a propósito de seus nus: «O modelo e eu estamos envolvidos em fazer uma pintura, não amor. São coisas que as pessoas que não são pintores têm dificuldade em entender.» (cf. SMEE, 2010, p. 55)

Um poema de Paulo Henriques Britto, em que se revela o material usado em sua produção, parece conjugar-se bem com essa Rapariga nua e com a produção de Lucian Freud. Trata-se de «Lorem ipsum» (2012, p. 11), de Formas do nada:

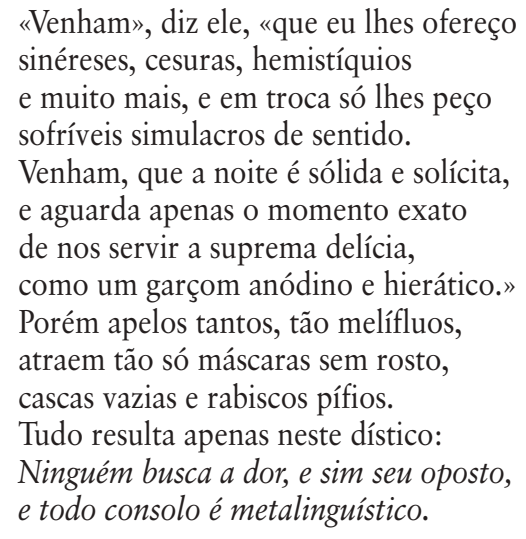

Bem adequado a iniciar um livro de poemas intitulado Formas do nada, «Lorem ipsum» parece dizer que os poemas serão mesmo «formas do nada», estratégias de preenchimento de espaços (impreenchíveis?). Que o leitor não se distraia com os textos, mesmo porque o original de "Lorem ipsum», que remonta ao século 45 a.C., dizia: «Não há ninguém que goste da dor em si mesma, que a procure e a queira ter, apenas porque seja uma dor...»

O poeta faz assim um jogo com o leitor: «Lorem ipsum», que seria um simples exercício de preenchimento de espaços, fala também de metalinguagem, mas também de oposição e consolo. Revela então, como a Rapariga nua, a ultrapassagem de uma dimensão humana que apenas caminharia em direção à morte, vencendo-a com essa "forma do nada», que fala justamente de nada, mas que com esse nada se comunica com o outro, o seu semelhante, para livrar a ambos da obrigação de ser, ou seja, para aliviá-los nessa expectativa e certeza do fim. 
Duas outras telas de Lucian Freud parecem conjugar-se com esse poema de Paulo Henriques Britto: Supervisora de Segurança Social a dormir (1995. Óleo sobre tela, $1,50 \times 2,50 \mathrm{~m}$, pesada também relativamente ao tamanho...), e À espera do quarto filho (2005. Óleo sobre tela, 10,2×15,2 cm.). Trata-se de figuras fortes que respondem ao desejo do pintor: «Só peço que [minha pintura] surpreenda, perturbe, seduza, convença.» (SMEE, 2010, p. 91) Embora pesada e volumosa, a Supervisora de Segurança Social a dormir realmente surpreende pela leveza da pincelada, pela harmonia da composição, pela adequação do sombreado e, ainda, pela suavidade do desenho do sofá.

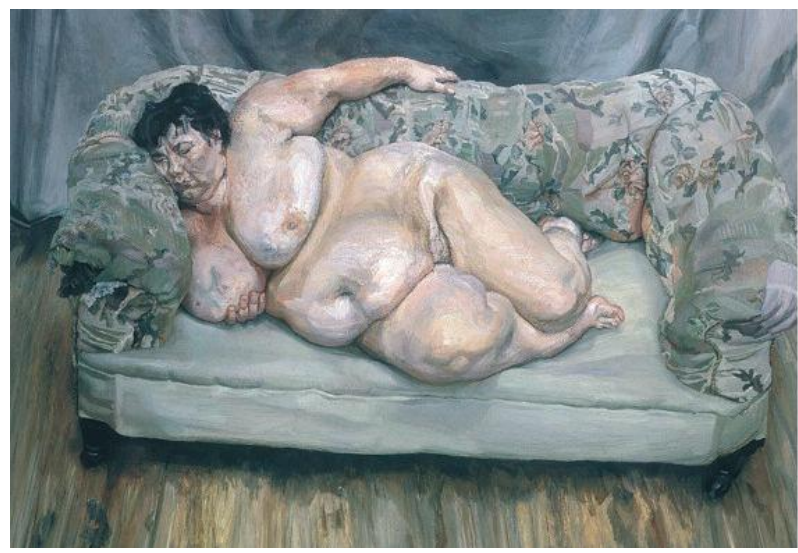

Já À espera do quarto filho, que mede apenas $10,2 \times 15,2 \mathrm{~cm}$, perturba pelo tamanho diminuto, pela aparente paralisia, pela quase separação da barriga do restante do corpo; mais que uma espera de vida, o quadro sugere a proximidade da morte. E o que mais chama a atenção é o registro do trabalho do pintor: a elaboração das formas e dos sombreados, e especialmente os rastos e restos de suas pinceladas, que lembram o que Britto chama de "cascas vazias e rabiscos pífios», no seu trabalho metalinguístico de «Lorem ipsum».

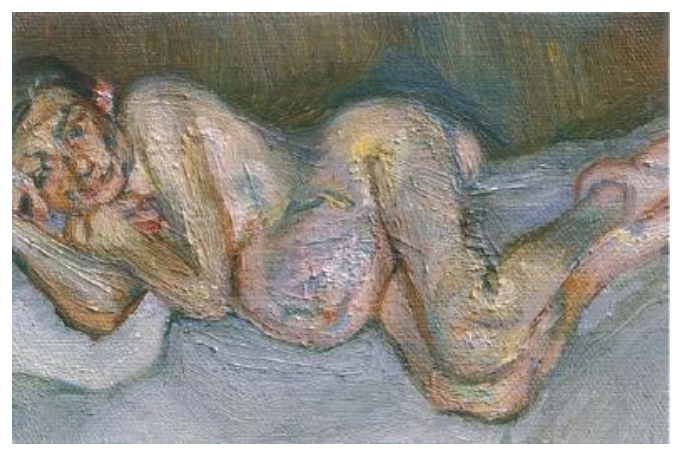


Para terminar, volto ao contrabando (ou à convergência?) cultural que percebo entre as obras de Lucian Freud e Paulo Henriques Britto. Creio que a contenção e a impotência nelas testemunhadas apontam para a humana nudez diante da morte e do nada; lembram entretanto que esses desafios e impulsos podem garantir a criação. O que diz Heloisa Jahn, na orelha do livro Formas do nada, de Paulo Henriques Britto, certamente poderia aplicar-se também a Lucian Freud: «o poeta, ao mesmo tempo frágil e irredutível, trata de organizar o mundo com sua voz de poeta, que é o instrumento com que percebe e captura o que talvez viva na sensação de vazio e de sem sentido».

\section{REFERÊNCIAS BIBLIOGRÁFICAS:}

Agamben, Giorgio. Bartleby - Escrita da potência. Lisboa: Assírio e Alvim, 20-.

Britto, Paulo Henriques. Formas do nada. São Paulo: Companhia das Letras, 2012.

FinazZI-Agrò, Ettore. «Tertium datur», in Duarte, Lélia Parreira. A escrita da finitude - de

Orfeu e de Perséfone. Belo Horizonte: Veredas \& Cenários, 2009, pp. 7-12.

FinAZZI-Agrò, Ettore. «Angst e sentimento (do) trágico na moderna poesia de Língua Portuguesa, Scripta. Belo Horizonte, CESPUC / PUC Minas, v. 12, n. ${ }^{\circ} 23,2 .^{\circ}$ sem. 2008, pp. 131-147.

Seligmann-Silva, Márcio. «A escritura da memória: mostrar palavras e narrar imagens». Dossiê «Literatura como uma arte da memória». Remate de males, 26.1., jan./jun. 2006, pp. 31-45.

- «As matrizes do abjeto: o homem-macaco. Estações de um tema», in Valores do abjeto. Niterói: EdUFF, 2008, pp. 27-38.

SILVA, Edson Rosa da. «Da representação do horror ao vazio da representação», in DiAs, Ângela Maria; GLENADEL, Paula. Valores do abjeto. Niterói: EdUFF, 2008, pp. 159-168.

SMEe, Sebastian. Freud. Koln: Tachen, 2010. 